\section{Desigualdades raciais e a morte como horizonte: considerações sobre a COVID-19 e o racismo estrutural}

\author{
Racial inequalities and death on the horizon: \\ COVID-19 and structural racism
}

\section{Desigualdades raciales y la muerte como horizonte: consideraciones sobre la COVID-19 y el racismo estructural}

\section{Resumo}

A incidência e mortalidade por COVID-19 em países com fortes desigualdades sociais se diferenciam em termos populacionais. Em países com histórico e tradição colonial como o Brasil, os marcadores sociais das diferenças têm profunda ancoragem na demarcação racial, sobre a qual agem as dinâmicas e os processos político-sociais fundados no racismo estrutural. Contrapõe-se a narrativas que propõem uma leitura sobre ser esta uma pandemia democrática, cujo argumento se alinha à retórica da democracia racial que corresponde a uma potente estratégia de manutenção do lugar de populações racializadas, como indígenas e negros, uma produção da colonialidade moderna. Este ensaio debruça sobre o comportamento da pandemia em relação à população negra no Brasil, em diálogo com aportes decoloniais e de leituras críticas sobre o racismo. Discutem-se respostas governamentais e indicadores da doença, segundo o quesito raça/cor, demonstrando a manutenção de tramas e enredos históricos que seguem vulnerabilizando e inviabilizando vidas negras. Aponta-se também para a importância de movimentos de resistência locais, operados a partir do lugar que esses sujeitos ocupam, os espaços urbanos precarizados por ação/omissão do Estado - as favelas.

COVID-19; Racismo; Vulnerabilidade Social

\author{
Roberta Gondim de Oliveira 1 \\ Ana Paula da Cunha 1 \\ Ana Giselle dos Santos Gadelha 1 \\ Christiane Goulart Carpio 2 \\ Rachel Barros de Oliveira 3 \\ Roseane Maria Corrêa 1
}

doi: 10.1590/0102-311X00150120

\author{
Correspondência \\ R. G. Oliveira \\ Departamento de Administração e Planejamento em Saúde, \\ Escola Nacional de Saúde Pública Sergio Arouca, Fundação \\ Oswaldo Cruz. \\ Av. Leopoldo Bulhões 1480, sala 720, Rio de Janeiro, RJ \\ 21041-210, Brasil. \\ robertagondim@ensp.fiocruz.br \\ 1 Escola Nacional de Saúde Pública Sergio Arouca, Fundação \\ Oswaldo Cruz, Rio de Janeiro, Brasil. \\ 2 Instituto Nacional de Saúde da Mulher, da Criança e do \\ Adolescente Fernandes Figueira, Fundação Oswaldo Cruz, \\ Rio de Janeiro, Brasil. \\ 3 CIDADES: Núcleo de Pesquisas Urbanas, Universidade do \\ Estado do Rio de Janeiro, Rio de Janeiro, Brasil.
}


A intensa circulação de pessoas e mercadorias no nível global foi determinante para a situação pandêmica da COVID-19. Surgida inicialmente no Hemisfério Norte, na China, em poucos meses estava na Europa e depois nos Estados Unidos, e destes foi para o Sul Global rapidamente. No Brasil, importado pelas classes média e alta, o vírus ajudou a forjar, inicialmente, um discurso reverberado pela imprensa de que seria uma doença que atinge a todos, cujas consequências são igualmente sentidas, isto é, uma doença "democrática”. Ressaltada, entretanto, apenas a questão da mortalidade diferenciada em determinados segmentos populacionais, como idosos e pessoas com morbidades preexistentes 1. Numa equivocada apropriação do conhecimento epidemiológico, as narrativas e decisões políticas produziram uma individualização da questão, retirando a perspectiva coletiva do adoecimento. Desse enfoque derivam não apenas controvérsias, como sobre o isolamento social, mas particulariza-se o problema como algo mais restrito a determinados indivíduos. Tem-se aqui uma questão ético-política 2, que é traduzida não apenas em diretrizes diferenciadas a depender do lugar que os indivíduos ocupam na estrutura socioeconômica, como no caso de jovens e da força de trabalho que representam na geração de bens e serviços, como também em protocolos assistenciais que definem as prioridades de acesso aos cuidados intensivos, como no caso de idosos e pacientes com comorbidades 3,4,5.

A segunda questão é relativa ao nosso processo societário e o mito da democracia racial 6, que serve para ocultar as relações raciais de subalternização, com base na ideia de miscigenação simétrica, ancorada na noção de uma sociedade livre do racismo. A crença no mito da democracia racial, sustentada por ideias que marcaram a sociedade brasileira contemporânea, mesmo que em alvo de questionamento e desconstrução por meio do ativismo dos movimentos negros, é reatualizada 7, retarda e impede o avanço esperado na discussão e na implementação de políticas e ações afirmativas 7,8.

A ideia de que a sociedade brasileira foi construída com base na convivência harmônica entre sua pluralidade racial imprime uma complexidade no processo de produção de uma identidade nacional, cujo ponto de chegada idealizado é representado pelo referencial branco europeu, de uma unidade étnica que opera o apagamento da identidade negra dos sujeitos "miscigenados" sob o ponto de vista discursivo, mas que não necessariamente implica em alterar seu lugar na estrutura social 9 .

Excetuando os segmentos com riscos diferenciados à COVID-19 já citados, os demais estariam, então, numa mesma escala de risco, logo não haveria necessidade de diferenciação nas políticas de enfrentamento da pandemia. As primeiras medidas caminharam nesse sentido, como o isolamento social propiciado pelo regime de trabalho remoto e reforço de práticas de higiene pessoal.

Ocorre que a realidade da classe trabalhadora de baixa renda, majoritariamente negra e moradora de territórios vulnerabilizados, é outra. São predominantemente trabalhadores precarizados, que não possuem o privilégio de ficar em casa, em regime de trabalho remoto; que utilizam os transportes públicos superlotados; têm acesso precário ao saneamento básico; e estão na linha de frente do atendimento ao público no setor de serviços, incluindo os de saúde. Foi baseando-se em pressões como o posicionamento de um conjunto ampliado de atores sociais (lideranças de favelas e político-partidárias progressistas), de atores do campo da saúde (acadêmicos, profissionais de saúde e gestores), parte da mídia e, fundamentalmente, com o desenrolar da pandemia no já evidente comportamento desigual que vem escancarando os marcadores sociais de desigualdades, principalmente o de raça, que esta passa a compor a preocupação e agenda de alguns atores sociais e governamentais.

É precisamente sobre a divisão racial do mundo e suas visíveis repercussões em face da pandemia da COVID-19 que propomos trazer para o debate. Olhar a pandemia sob a luz das desigualdades raciais impõe-nos pensar não apenas os números que as revelam, que sim, são importantes, mas fundamentalmente sobre a trama, historicamente tecida, que lhe confere estrutura, dinâmicas e práticas narrativas.

\section{A COVID-19 escancara a divisão racial do mundo}

A pandemia da COVID-19 tem provocado análises críticas de diversos campos do conhecimento, que vão desde a perspectiva biomédica, passando por reflexões geopolíticas, sociais, subjetivas e econômicas, de modo a apresentar interpretações e proposições sobre o seu efeito no mundo. Entretanto, as tentativas de respostas não acompanham a velocidade de transmissão da doença. As experiências de morte, adoecimento, isolamento e restrição de circulação de pessoas, associadas às incertezas de 
ordem epidemiológica, social e econômica, atravessam cotidianos do Norte ao Sul Global, com destaque para este último. Ao analisar tais realidades, reconhecemos a heterogeneidade nos modos de viver esta pandemia, especialmente para os povos subalternizados, cujos corpos são historicamente forjados pela ameaça cotidiana da morte e pelo sofrimento dos efeitos das desigualdades, imprimindo um verdadeiro genocídio seletivo 6 .

Baseando-se na perspectiva decolonial e dos aportes conceituais de Mbembe, tais como "necropolítica" 10 e "devir-negro do mundo" 11, endossando o coro de vozes que denunciam o caráter racista, genocida e mortífero do projeto moderno colonial da sociedade ocidental, trataremos a partilha geográfica racial evidenciada pelos rastros de morte e adoecimento da COVID-19 em populações, especialmente a negra. A COVID-19, em seu espraiamento global de caráter pandêmico, não apenas expõe as desigualdades, como reatualiza e reifica as demarcações coloniais de base racial, que são fundantes do mundo moderno, tendo na delimitação Norte/Sul, sob o ponto de vista geográfico e sociológico, uma de suas principais ancoragens.

A perspectiva decolonial representa uma contrapartida à noção naturalizada da colonialidade contemporânea como expressão de "uma lógica global de desumanização" 12 (p. 36), que não encerra com o fim do colonialismo. Mignolo 13 formula a tese de que a modernidade detém um lado oculto formado pela colonialidade, propagadora de uma narrativa eurocêntrica cuja ideia de "salvação" e "novidade" esconde a expropriação e, assim, se apresenta para os territórios não europeus. Justifica-se, portanto, em nome de um projeto civilizatório, as práticas de dominação, exploração, expropriação e morte. Para Maldonado-Torres ${ }^{12}$, o paradigma da guerra e da violência contra os sujeitos colonizados orienta o projeto modernidade/colonialidade. A modernidade tem no projeto de colonização uma de suas principais égides, estando hoje em outra roupagem, respondendo ao projeto da colonialidade, na medida em que preserva os elementos classificatórios do mundo, atualizando-os dinamicamente 14. O poder capitalista da modernidade, de ordem colonial, está ancorado na "imposição da classificação racial/étnica da população do mundo como pedra angular do referido padrão de poder" 15 (p. 84).

Como a colonialidade do poder revela a conformação de um padrão de poder tendo na noção de raça seu pilar, está dada a condição para se efetuar a definição do outro não branco como "índios", "negros" e "mestiços" enquanto novas identidades sociais, acopladas às relações coloniais de dominação e exploração estabelecidas entre europeus e não europeus. Essa diferenciação determina estamentos, lugares e papéis na estrutura de poder, tendo por sustentáculo os regimes de trabalho de servidão e escravidão. A díade raça/trabalho forçado contribuiu para a emergência de uma nova estrutura de relação de produção mundial no período colonial, que é fundada na desumanização do "outro" e, ressalta-se, não cessa com o fim do colonialismo 12 . A colonialidade propaga uma narrativa eurocêntrica em nome de um "projeto civilizatório", com base em práticas de dominação, expropriação e morte. Diferentemente do colonialismo tradicional, que encerra mediante a emancipação político-administrativa das colônias ou com o fim de excursões exploratórias, a colonialidade permanece, fundando relações de poder profundas, indo além das searas econômicas, políticas e de trabalho, atravessando as relações sociais e as constituições intersubjetivas 15,16 .

A perspectiva eurocêntrica de conhecimento, ao conservar a ideia de raça como critério de classificação social, expropria dos povos originários e daqueles provenientes do continente africano suas linguagens, histórias, conhecimentos, memória, reduzindo-os a uma massa uniforme sem ou quase nenhum valor nos termos de humano. Destituídos de humanidade, coisificados, tratados como inferiores que precisam ser dominados e explorados, os "não-europeus" foram deixando de ter nome, história, memória e língua própria 11, e ainda carregam, em seus corpos, a ferida aberta e pungente do trauma colonial 17. O racismo como processo de reprodução de desigualdades de povos, forjado com base nos atributos do corpo, é anterior à formulação da noção de raça, que produz então seres cuja identidade se encerra em ser "negro" e "índio", como exemplos 18.

A lógica racista está no cerne de práticas necropolíticas, operadas também no contexto de enfrentamento à COVID-19, especialmente nos territórios periféricos onde vivem majoritariamente a população negra e pobre. O conceito de necropolítica tem sido utilizado para compreender a relação entre Estado e um padrão de genocídio de populações racializadas. Essa perspectiva discute com o conceito foucaultiano de biopoder, ressaltando o racismo como elemento central do exercício do poder estatal, legitimando o direito de deixar morrer e/ou de matar, em nome da sustentação de determinados modos de reprodução de outras vidas mais legítimas 10. "A característica mais original 
dessa formação de terror é a concatenação entre biopoder, o estado de exceção e o estado de sítio. A raça é, mais uma vez, crucial para este encadeamento" 10 (p. 31). Ou seja, outras configurações de existência social em que as populações apresentem condições de vida que as conferem estatuto de "mortos-vivos", nos termos de Mbembe 10 (p. 71).

No cenário atual de países com histórico colonial, como o Brasil e os Estados Unidos, esse contingente vai rapidamente se deslocando para compor o crescente aumento de corpos majoritariamente negros mortos pela epidemia. Essa "humanidade supérflua" 10,19, com lugar e função pré-definidas no funcionamento capitalista, vem encontrando destino em covas coletivas abertas diariamente, resultante desse ordenamento necropolítico, no qual o poder da morte é soberano ao direito à vida. "A justificação da morte em nome dos riscos à economia e à segurança torna-se o fundamento ético dessa realidade” 10 (p. 124). Portanto, questionamos: se seguirmos assim seria o "devir-negro do mundo" 11 o saldo que desponta no horizonte ao fim desta pandemia? Ao mapear as dinâmicas da civilização moderna ocidental, em que o argumento racial esteve na origem de massacres e crimes, Mbembe identifica no século XXI, sob a égide do capital financeiro, a imensa ascensão de uma humanidade excedente, sem qualquer função para o sistema capitalista - o surgimento de homens-coisa, homens-máquina submetidos às exigências do capitalismo 11 .

\section{Olhar a pandemia sob a luz das desigualdades}

Como seguir justificando a ação diferenciada do Estado sobre populações territorial e materialmente colocadas à margem daquilo que se reconhece como direito pleno da cidadania, tendo na saúde um importante fundamento? Em 1850, o Rio de Janeiro foi acometido pelo surto de febre amarela, doença que ficou conhecida como vômito negro, e tem importância fundamental para a compreensão da questão racial como política. Nesse período, a febre amarela atingia sobretudo imigrantes europeus trazidos como substitutivos à mão de obra escrava, que por sua vez não poderia assumir o estatuto de assalariado inserido nas estruturais formais do Estado de direito, portanto, seguindo à margem do estatuto da cidadania. A inserção de negros no mercado de trabalho impediria a conformação de uma classe trabalhadora considerada como "moralmente aceitável" 20.

Os negros libertos e os ainda escravizados, por sua vez, tinham baixa contaminação por essa doença se comparados a outras enfermidades, como a varíola e a tuberculose, que já estavam presentes no país há mais tempo. Ainda assim, a febre amarela assumiu lugar de destaque na agenda da saúde pública. Segundo Chalhoub 20, no final do século XIX, os negros foram identificados como mais resistentes às enfermidades e mais aptos ao trabalho pesado.

As desigualdades raciais que percebemos hoje têm ancoragem nas políticas que, desde a pós-abolição, limitaram as oportunidades da população negra. De acordo com Hasenbalg 21, a política de imigração de estrangeiros é a principal medida que explica a marginalização de negros no Sudeste e a distribuição de não brancos nas regiões do país com oportunidades educacionais e ocupacionais limitadas. O autor também ressalta que, na medida em que nos afastamos do período escravista, as relações estruturais e os princípios racistas de seleção e estratificação social ganham mais relevância para explicar as oportunidades diferenciadas entre brancos e negros, bem como para a compreensão da transmissão intrageracional e intergeracional das desigualdades raciais 21 .

Guardadas as devidas singularidades contextuais, o fato observado não é exclusividade da época e refaz-se ao longo da história. Essa alusão ajuda a compreender dinâmicas do presente. Outro exemplo significativo é relativo à tuberculose, quando em meados dos anos 1990 a Organização Mundial da Saúde (OMS) reinsere a doença em sua agenda de prioridades por causa do grande aumento da mortalidade em função da coinfecção com HIV, sendo esta considerada como uma doença reemergente. Essa denominação serve para designar doenças que foram controladas ou suprimidas em termos globais, mas que em algum momento retornam significativamente. Ocorre que a tuberculose nunca deixou de ser um grave problema de saúde pública em diversos países considerados como periféricos, assim como em determinadas regiões ou mesmo bairros de países centrais, como aqueles que concentram as populações afrodescendentes nas grandes cidades estadunidenses, ao que Farmer 22 denomina como a "vingança da tuberculose". Não ser mais um problema de saúde para as populações centrais do sistema mundo 23 significa passar a ser secundarizada em termos de atenção e de recursos, havendo, 
portanto, um "silenciamento da situação da tuberculose, como questão social, econômica e de saúde sobre populações pobres do mundo - com altas taxas de incidência e de mortes” 24 (p. 2295).

A pandemia da COVID-19 no Brasil demonstra que regiões e populações são colocadas em condições de maior vulnerabilidade aos riscos de contaminação e morte. Partimos desses pressupostos para analisar o cenário nacional da pandemia da COVID-19. O país ocupa a 79a posição no ranking de desenvolvimento humano da Organização das Nações Unidas 25. Nos últimos anos, vê-se um aumento dos indicadores de desigualdade, atingindo sobretudo a população negra. Em 2018, no Município do Rio de Janeiro, 30,5\% das pessoas negras (pretas e pardas) residiam em favelas, contra 14,3\% de pessoas brancas 26 . Em termos de cobertura de saneamento básico, negros são a maioria vivendo em locais com infraestrutura inadequada e exposição a vetores de doença: 12,5\% de negros residem em locais sem coleta de lixo e apenas $6 \%$ da população branca; sem abastecimento de água por rede geral, os negros representam $17,9 \%$, e brancos $11,5 \%$; sem esgotamento sanitário por rede coletora ou pluvial, negros representam $42,8 \%$ da população contra $26,5 \%$ de brancos 26 .

A desigualdade é evidente ao observarmos que 32,9\% dos negros compõem a parcela de brasileiros que vivem com até USD 5,50 por dia, além daqueles que vivem na linha da extrema pobreza, com rendimento de até USD 1,90 por dia $(8,8 \%) 26$. O adensamento domiciliar excessivo dificulta o cumprimento das medidas de distanciamento intradomiciliar, recomendada para os casos positivos de COVID-19. Em abril de 2020, foi publicado o Decreto no 10.32927 que desobriga o fornecimento de serviços públicos e atividades essenciais, revogando, entre outros, a captação, o tratamento e a distribuição de água, e a captação e o tratamento de esgoto e lixo, agravando a situação de vulnerabilidade em locais já precarizados.

Constata-se também que no Brasil há estratificações estruturais desfavoráveis à inserção social da população negra no mercado de trabalho. Apesar de corresponderem, em 2018, a 55,8\% da população nacional 26, são 64\% dos desocupados e 66,1\% dos subutilizados 28; esta informação fornece um dos contornos da vulnerabilidade quanto à garantia de subsistência desse grupo populacional. Ademais, atravessamos uma crise política e econômica com retrocessos e retirada de direitos trabalhistas. No contexto da pandemia, o risco de contaminação do atendente de enfermagem é de 97,3\%, dada a manipulação direta do corpo do paciente 29 . O uso de equipamentos de proteção individual é primordial para a proteção do profissional, porém o fornecimento tem sido inadequado. Há também déficit de profissionais, questão agravada diante do alto número de afastamentos por contaminações 30 . Em face da gravidade da questão, foi criado um Gabinete de Crise para acompanhar diariamente o impacto da pandemia de COVID-19 nas(os) profissionais de Enfermagem 31.

A enfermagem é uma categoria profissional majoritariamente feminina e negra 32, que está atuando na linha de frente dos cuidados às vítimas da COVID-19. Por serem mulheres, cumprem uma dupla jornada de trabalho, sendo que segundo o Instituto Brasileiro de Geografia e Estatística (IBGE) 26 em 2019, em torno de $45 \%$ da população negra residiam em domicílios sem máquina de lavar, "isso constitui indício de que a população preta ou parda, em especial as mulheres, tem maior carga de trabalho doméstico" (p. 6) 26. A associação entre estar na linha de frente dos cuidados à COVID-19, a precariedade habitacional e a sobrecarga do trabalho doméstico ampliam tanto a probabilidade de contágio no domicílio quanto do seu próprio adoecimento.

Outro agravante está relacionado aos portadores de doenças crônicas e aqueles acima de 60 anos, considerados grupo de risco, que não necessariamente são afastados das suas atividades 33 . Nesse sentido, o impacto social da pandemia na categoria profissional de enfermagem deve ser prioridade na agenda da gestão.

\section{A favelização da COVID-19 e a demarcação racial}

O primeiro caso da COVID-19 no Brasil foi confirmado em 26 de fevereiro de 2020 34, em São Paulo, sendo a epidemia declarada como emergência em saúde pública em 3 de fevereiro de 202035.

Concentrado inicialmente na Região Sudeste, especialmente nas cidades de São Paulo e Rio de Janeiro, mas em vista de insuficientes ações de controle com o consequente aumento do contágio, a doença alastrou-se para o restante do país, com repercussões altamente negativas em termos de número de casos e mortes no Norte e Nordeste, regiões que já enfrentavam crônicos problemas 
infraestruturais dadas as desigualdades regionais. Ainda que tenham sido atingidas, as regiões Sul e Centro-oeste não estavam, nos meses de abril e maio de 2020, em situação tão crítica como as demais 36. Como a COVID-19 não atinge grupos e locais simétrica e democraticamente, é nas periferias e favelas, locais com os piores indicadores de desenvolvimento humano, que a pandemia apresenta sua face mais cruel.

Os estados que ocupavam, na segunda quinzena de maio de 2020, os primeiros lugares no ranking de casos - São Paulo, Rio de Janeiro, Ceará, Amazonas e Pará - tinham, no mesmo período, regiões e bairros com índices de letalidade acima da média nacional (5,7\%) 36. Em São Paulo, o bairro de Brasilândia, que concentra mais de 50\% da população residente negra 37 e a segunda maior quantidade de favelas 38, registrou, no final de maio de 2020, 4.943 casos de COVID-19 confirmados e a maioria das mortes: 209 óbitos entre confirmados e suspeitos 39 . No extremo oposto da cidade, os bairros centrais apresentam as menores taxas de contaminação e óbito. Os territórios mais pretos da cidade são marcados pela distribuição desigual de leitos de UTI: 60\% estão no centro 40.

Fortaleza, no Ceará, concentrou 21.389 casos e 2.120 óbitos até o final do mês de maio de 202041. A dinâmica de contágio, que iniciou por bairros ricos e turísticos, como Aldeota, Meireles e Dionísio Torres, mudou, nesse mesmo período, para os bairros mais empobrecidos, como Grande Pirambu e Barra do Ceará, que são contíguos à zona litorânea, evidenciando a estreita relação entre mortalidade e precariedade. Esses locais de extrema vulnerabilidade, e que dependem do Sistema Único de Saúde (SUS), são os mais afetados pela pandemia.

A necessidade de acesso ao SUS nessa conjuntura expõe a fragilidade de um sistema em processo de desmonte. Ao longo dos meses de abril e maio 2020, São Paulo, Rio de Janeiro, Ceará, Pernambuco e Amazonas atravessaram a grave situação de falta de leitos na rede de saúde 42. Em Manaus, Amazonas, no final do mês de maio de 2020, não havia mais leitos públicos para internação, o colapso do sistema de saúde no Amazonas reverberou em 2.047 óbitos com um atroz cenário de pacientes ao lado de cadáveres nos ambientes hospitalares 36 . Alarmante também é a situação da população indígena, tendo, na última semana de maio, Manaus com 92 casos oficialmente e aumento deste número no Alto do Rio Solimões, localidade que registrou 351 casos, no mesmo período 43.

Na capital do Rio de Janeiro, os primeiros casos surgiram em bairros de classes média e alta, migrando para as áreas de favelas. Até 31 de maio de 2020, houve um total de 260 mortes nas grandes favelas, com destaque para Rocinha e Maré, com 55 e 48, respectivamente 44. Em São Conrado, bairro que faz limite com a Rocinha, foram contabilizados três óbitos até o dia 7 de maio de 2020 45. Na Baixada Fluminense, um dos territórios mais pobres e violentos do estado, foi amplamente divulgada, na segunda quinzena de abril de 2020, a adoção do uso de contêineres para a permanência temporária de corpos, como em Duque de Caxias, devido ao aumento de óbitos e problemas de contágio nos cemitérios 46. Esse município, no fim do mês de maio de 2020, concentrou 1.502 casos, precedido por Nova Iguaçu com 1.77047.

Diante da escassez de informações epidemiológicas precisas, com recorte de favelas, e da agenda estatal errática e insuficiente do enfrentamento à COVID-19 nesses espaços, tem havido o surgimento de iniciativas lideradas por coletivos locais, que demonstram a potência organizativa da ação local em situação de emergência, a despeito da ausência do poder governamental, com arrecadação e fornecimento de alimentos, material de limpeza e higiene pessoal; acesso à água; geração de renda; mutirão de limpeza urbana e comunicação. Destacam-se o Gabinete de Crise do Complexo de Favelas do Alemão, que agrega três movimentos - Voz das Comunidades, Mulheres no Alemão em Ação e Coletivo Papo Reto; o Painel COVID-19 nas Favelas, que monitora e informa diariamente os números da epidemia em alguns dos maiores complexos de favelas do Rio de Janeiro; o Fundo Emergencial do Movimento Nacional dos Trabalhadores Sem-Teto para os afetados pelo coronavírus; a iniciativa Corona nas Periferias, parceria entre a Favela em Pauta, uma iniciativa de jornalistas populares, e o Instituto Marielle Franco, que cadastram e apoiam iniciativas de combate ao coronavírus em favelas e periferias de o todo o Brasil 44. A noção de "nós por nós" é fundante dessas iniciativas, pois partem do princípio de ações e resistências gestadas e criadas autonomamente pela população favelada e negra, de ancoragem ancestral e afrodiaspórica 48.

A construção de um sentido de mundo afrodiaspórico, produzido com a tomada de consciência coletiva amalgamada com base em uma história comum, é forjada quando ao percorrer a travessia do Atlântico os sujeitos passaram a ter seus corpos e vidas marcados pela exclusão e desumanização. A 
chave para a reumanização envolve enfrentar os processos de expropriação do ser, retomar o sentido de identidade pelo coletivo e de produzir estratégias de resistência e de cuidado em grupo 48.

\section{A desigual distribuição das mortes em termos internacionais e nacionais - o que dizem os números da pandemia sobre vidas negras?}

A desigualdade de raça, como um importante marcador social das diferenças, é invisibilizada em variados aspectos, tendo na saúde um importante exemplo. Indicadores de saúde segundo o quesito raça/cor não são satisfatoriamente registrados, consequentemente, as análises são questionáveis. Essa é uma pauta antiga de reivindicação dos movimentos negros 49 . No período de redemocratização brasileira, mesmo com o surgimento de pesquisas desvelando as iniquidades raciais no Brasil 50, e mais recentemente com um conjunto de políticas afirmativas, ainda não se conseguiu garantir plenamente o registro do quesito raça/cor em vários indicadores sociais e de saúde. No atual contexto, há uma grave subnotificação nas taxas de incidência e mortalidade por COVID-19. No sentido de reverter a persistência de práticas discriminatórias na condução da COVID-19, foi feita a exigência da aplicação da Portaria GM/MS no 344, de 2017, que trata do preenchimento obrigatório do quesito raça/cor nos atendimentos em serviços de saúde 51. Embora esse item faça parte do rol de objetivos específicos da Política Nacional de Saúde Integral à População Negra (PNSIPN) de 2009 52, sua consolidação permanece frágil.

Resultado de uma luta histórica do movimento social negro pela democratização da saúde e promoção da equidade racial, essa política se destaca pela transversalidade de suas ações e estratégias, assim como pelo reconhecimento do racismo e das desigualdades étnico raciais como parte da determinação social da saúde. A criação dessa política foi incorporada a um conjunto de outras estratégias governamentais propostas com vistas à redução dos indicadores de adoecimento e morte dessa população historicamente mais vulnerabilizada. O texto da política contemplou ações abrangentes voltadas para a atenção, promoção e prevenção de doenças, assim como para a participação nas instâncias de controle social e formação e educação para os trabalhadores da saúde. Entretanto, apesar da PNSIPN se apresentar como um potente instrumento de constrangimento de ações e práticas discriminatórias promotoras e sustentadoras das iniquidades em saúde, a sua insatisfatória implementação persiste. Para Werneck 53, tanto o rechaço explícito quanto a ignorância acerca dos elementos que compõem essa política são fatores que levam a esse cenário.

Registros em saúde são estratégicos e fundamentais para o conhecimento das condições de morbimortalidade de populações e a tomada de decisão de gestores governamentais. Nos Estados Unidos, país de histórico colonial escravagista como o Brasil, essas informações são mais frequentes nos dados oficiais, possibilitando demonstrar o impacto das dinâmicas político-sociais racializadas sobre vidas negras. Não cabe no espaço deste ensaio a discussão sobre o tema, porém pontua-se que contextos históricos diferenciados, marcados pelo binômio apartheid versus mito da democracia racial, implicam traços também diferenciados de processos políticos de sociabilidade e de subjetivação.

$\mathrm{Na}$ cidade de Chicago, a população negra representa $29 \%$ da população total, porém, correspondeu, até a primeira semana de abril de 2020, a 70\% das mortes por COVID-19. No mesmo período em Michigan, cuja proporção populacional de negros é de 14\%, sendo apenas $30 \%$ dos casos positivos testados, correspondem a perturbadores $40 \%$ das mortes 54 . A população negra enfrenta sérias barreiras de acesso aos serviços de saúde e condições precárias de moradia e trabalho. Em relação à testagem, os dados da segunda quinzena de abril de 2020 se mostraram significativos: baixo porcentual de negros testados $(13,2 \%)$, díspare em relação ao de mortes $(38,1 \%) 55$. São pessoas postas à margem das ações de saúde, mas que se fazem presentes, massivamente, no número de óbitos, demonstrando a seletividade da política de saúde.

Análises como a de Dorn et al. 56 também reforçam que a pandemia em solo estadunidense serve para confirmar as disparidades existentes. Em Nova York, Estados Unidos, e outros centros urbanos, onde há forte presença afro-americana e hispânica, o número de mortes por COVID-19 foi, em abril de 2020, desproporcionalmente alto em comparação com a população em geral 56. Em outras localidades, como Milwaukee (Wisconsin), três quartos das mortes por COVID-19 foram de afro-americanos, também em abril de 2020. As desigualdades raciais preexistentes imprimem os contornos das desi- 
gualdades em saúde de negros, latinos e demais minorias, que suportam um peso desproporcional da ineficiência estatal, de um governo ultraliberal, em evitar a propagação da doença 56 .

A população negra norte-americana, em comparação à branca, tem os piores indicadores de saúde: menor expectativa de vida ao nascer, maior proporção de pessoas vivendo abaixo da linha da pobreza, maiores taxas de mortalidade infantil, maior taxa de mortalidade relacionada à diabetes, dentre outros 57 . O racismo estrutural tem reverberação no acesso da população afro-americana ao mercado de trabalho e nas condições de moradia. Há uma evidente segregação racial no território norte-americano, de forma que há bairros onde a população residente é majoritariamente negra. Esses locais têm precárias condições de vida, como a exposição a poluentes e toxinas, além de limitadas oportunidades de acesso ao sistema educacional e à saúde de qualidade 57 .

Em termos de trama social de base colonial, Estados Unidos e Brasil se aproximam, porém, se diferenciam em vários aspectos, como na representatividade quantitativa da população negra, de 13\% 58 a 57,8\% 26, respectivamente. Além disso, diferentemente dos Estados Unidos, o Brasil conta com um sistema universal de saúde, com o pressuposto de cobrir as necessidades de saúde de toda a população. Entretanto, também apresenta grandes disparidades nos indicadores sociais, em face das desigualdades sociorraciais.

No início da epidemia em território nacional, o Ministério da Saúde estruturou um sistema de monitoramento e avaliação, divulgando sistematicamente Boletins Epidemiológicos sobre a evolução da doença, mas que não contemplava informações discriminadas por raça/cor. Após pressão dos movimentos negros, liderada pelo Instituto Luiz Gama e Defensoria Pública da União, a Justiça Federal do Rio de Janeiro determinou a obrigatoriedade do registro e publicização dos dados da COVID-19 segundo esse quesito 59. O Ministério da Saúde passou a publicar esses registros nos Boletins Epidemiológicos a partir de 11 de abril 60. Entretanto, há um alto porcentual de informação sobre raça/cor ignorada, o que mantém o padrão de subnotificação e, consequentemente, dificulta as análises sobre as disparidades raciais.

O governo brasileiro vem apresentando repostas erráticas e não alinhadas às diretrizes internacionais lideradas pela OMS, tampouco às evidências já sistematizadas pelos países que enfrentam a pandemia há mais tempo. Esse não alinhamento é constatado em diversas dimensões - ausência de uma concertação federativa em relação às medidas de contenção do contágio como o isolamento social, com destaque a não adesão do governo federal; ausência de um efetivo sistema de proteção social para as populações mais vulnerabilizadas; adesão a medidas terapêuticas controversas e não consensuadas pelas sociedades científicas nacionais e internacionais; não priorização da estratégia de testagem dos sintomáticos respiratórios e dos mais expostos; baixa efetivação na ampliação da oferta de dispositivos de cuidados intensivos hospitalares e insuficiente abastecimento de recursos críticos ao tratamento da doença.

Ademais, ao longo de dois meses e meio desde o início da pandemia houve duas mudanças de Ministro da Saúde. Portanto, a implementação de uma sistemática divulgação dos índices da doença em território nacional, iniciada pela primeira gestão do Ministério da Saúde a enfrentar a pandemia sofreu descontinuidade, havendo uma redução na periodicidade da divulgação dos Boletins Epidemiológicos. São elementos que evidenciam uma questionável condução nas políticas em face à emergência sanitária, dificultando o planejamento, o monitoramento e o controle da disseminação da doença.

Nas análises que seguem utilizamos os dados dos Boletins Epidemiológicos (https://coronavirus. saude.gov.br/boletins-epidemiologicos, acessado em 30/Mai/2020) identificados por Semanas Epidemiológicas (SE). No caso da divulgação de mais de um boletim em uma mesma SE, considerou-se o boletim mais recente daquela semana.

As informações estão desagregadas no quesito raça/cor e, para fins deste trabalho, operamos a agregação das categorias preta e parda sob a categoria negra, conforme definido pelo IBGE 26,61 e referendado pelo Instituto de Pesquisa Econômica Aplicada (IPEA) 62. Na proporção de hospitalizações e óbitos por COVID-19, observa-se que inicialmente nos brancos o percentual de internações e mortes foi maior quando comparado aos negros. Entretanto, no decorrer das SE identifica-se uma redução da proporção de óbitos e hospitalizações entre brancos (Figura 1). Em contrapartida, os óbitos e hospitalizações na população negra aumentam. Verifica-se também que em negros há uma baixa proporção de hospitalização, quando em comparação com a proporção de óbitos (Figura 1), o que sinaliza desigualdades no acesso a serviços de saúde e maior vulnerabilidade populacional. Pontua-se mais uma 
vez, entretanto, o alto porcentual de informações desagregadas por raça/cor ignoradas tanto entre as hospitalizações quanto entre os óbitos, podendo ser esta diferença ainda maior.

Destaca-se, portanto, a magnitude da queda de internações e óbitos em brancos e o aumento em negros, em poucas semanas (Figura 2), o que indica o percurso trilhado pelas desigualdades raciais, mostrando a manutenção do enredo político-social racializado no qual vidas negras estão submetidas. Verifica-se que na SE 15 a proporção de hospitalizações era de 73\% na população branca e de 23,9\% entre os negros. No decorrer do período segue a tendência de hospitalização entre brancos e aumento entre negros, alcançando uma paridade de 49\% das hospitalizações na SE 21, mas com uma discreta diferença a maior entre negros.

\section{Figura 1}

Hospitalizações e óbitos por síndrome respiratória aguda grave segundo raça/cor, de acordo com as Semanas Epidemiológicas (SE).

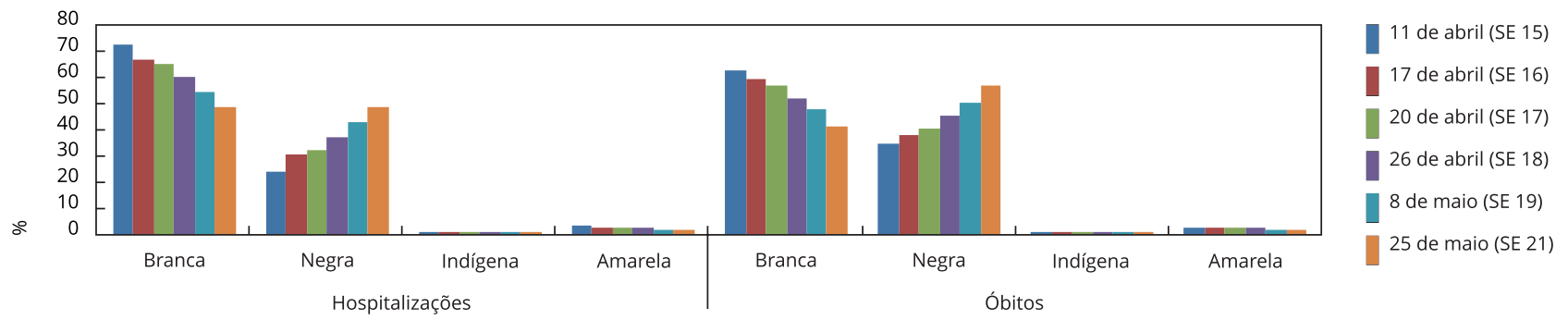

Fonte: Ministério da Saúde. Boletins Epidemiológicos COVID-19 (https://coronavirus.saude.gov.br/boletins-epidemiologicos, acessado em 30/Mai/2020).

\section{Figura 2}

Proporção de hospitalizações por COVID-19, segundo raça/cor, dia da divulgação e Semana Epidemiológica (SE).

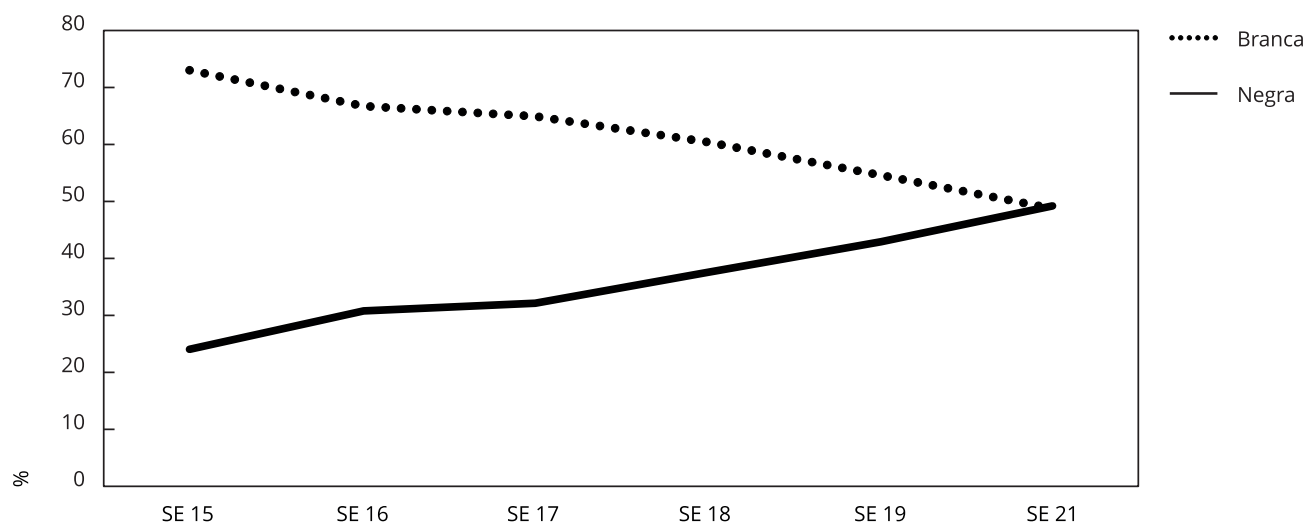

Fonte: Ministério da Saúde. Boletins Epidemiológicos COVID-19 (https://coronavirus.saude.gov.br/boletins-epidemiologicos, acessado em 30/Mai/2020). 
Já o número de óbitos de negros supera o de brancos, ainda que a hospitalização não acompanhe esta tendência (Figura 3). O que reforça a análise sobre a dificuldade de acesso dessa população aos serviços de saúde, principalmente os de maior complexidade, como os leitos de cuidados intensivos, cujo recurso tem sido crítico no atual contexto. Identifica-se que a evolução da proporção de óbitos, do primeiro boletim em que houve a estratificação por raça/cor, ao último boletim, é de 62,9\% para $41 \%$ em brancos e de 34,3\% para 57\% em negros. Essa tendência deve se manter ao longo das próximas semanas, diante da forte chegada da doença aos territórios periféricos - as favelas, onde a população negra é majoritária 26. Segundo o Painel COVID-19 nas Favelas, até o final do mês de maio de 2020 houve em torno de 266 óbitos em um conjunto de favelas do Rio de Janeiro, como Rocinha, Manguinhos, Maré, Jacaré, Alemão, Jacarezinho, Cidade de Deus, entre outras 44.

Outros estudos chegaram a conclusões semelhantes, reforçando a constatação sobre a maior letalidade em negros e expondo uma grande diferenciação nas chances de morte segundo raça/cor um paciente negro analfabeto tem 3,8 vezes mais chances de morrer em relação ao branco com nível superior 63 .

Esse desigual comportamento da doença entre as populações brancas e negras, com desfavorável tendência para estas últimas, vem ratificar as análises sobre as desigualdades raciais, resultantes de nossa matriz colonial que naturaliza o lugar de mundo destinado a cada um a depender de sua raça, também esta uma construção política. Sobre a insatisfatória qualidade das informações desagregadas segundo raça/cor, salientamos que o não registro merece destaque. Discussões sobre raça têm sido preocupação de negras e negros, pois que racializadas nos termos aqui debatidos. Não compõe o rol de preocupações da maioria dos não negros, devido tanto à naturalização do privilégio daqueles, como da subalternização destes. A questão de raça importa aos racializados - negros, indígenas, amarelos etc. - num mundo em que o branco é concebido como universal. Isso representa uma inversão, já que o problema do racismo não é localizado e discutido na sua origem, onde efetivamente é produzido, e sim na sua consequência, ou seja, em vidas racializadas 65 .

A ausência do registro dessa variável também revela o racismo, nos moldes institucionais, pois impede que vejamos a verdadeira magnitude da exclusão da população negra. Essa constatação remete a uma das dimensões da necropolítica: há corpos cujos perfis de morbimortalidade nem são registrados, pois que classificados como descartáveis e supérfluos 10. A publicização desse registro pode provocar o questionamento sobre a legitimidade do mito da democracia racial 6, argumento potente a

\section{Figura 3}

Proporção de óbitos por COVID-19, segundo raça/cor, dia da divulgação e Semana Epidemiológica (SE).

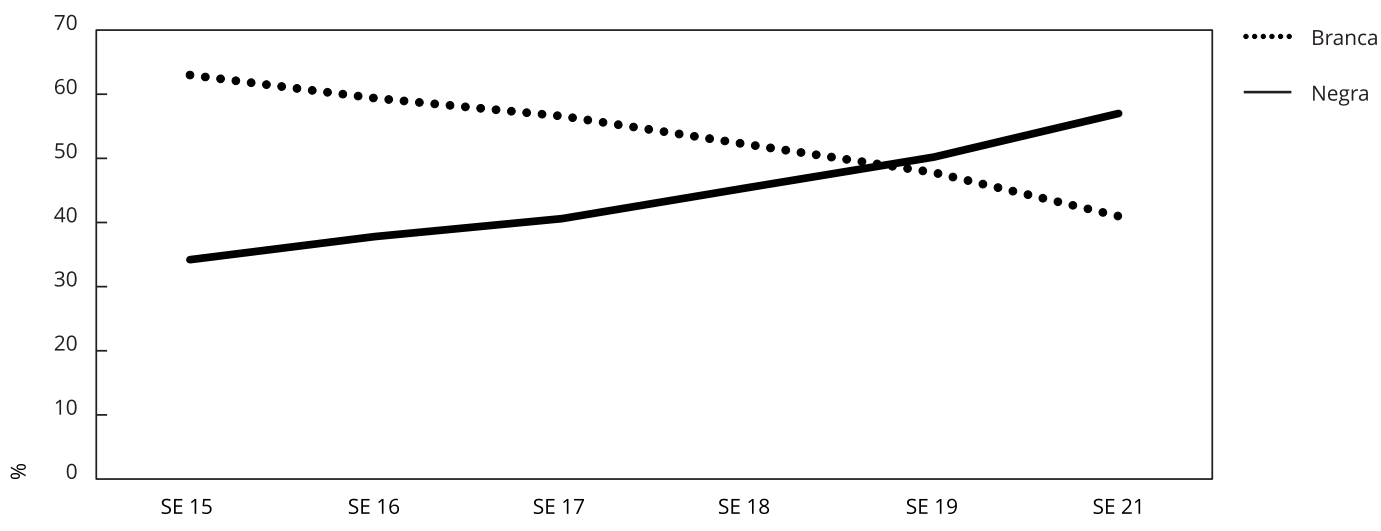

Fonte: Source: Ministério da Saúde. Boletins Epidemiológicos COVID-19 (https://coronavirus.saude.gov.br/boletinsepidemiologicos, acessado em 30/Mai/2020). 
serviço do apagamento do racismo como traço social, responsável por um dado equilíbrio social que mantém negros e negras no "inquestionável" lugar de subalternidade. O desvelamento das estruturas político-sociais racializadas poderia abrir caminho para outra compreensão desse lugar previamente marcado, portanto, pergunta-se a quem interessa não explicitar as diversas faces do genocídio da população negra?

Questionar e resistir são importantes, e já se percebe certa visibilidade da discussão sobre o acometimento da população negra pela COVID-19 em alguns espaços, como nos meios de comunicação, em debates científicos e em determinadas agendas governamentais. A visibilidade da problemática, pressionada a partir das vozes negras principalmente da periferia, continua a ser parte da bandeira de luta antirracista, majoritariamente levantada pelo povo negro.

\section{Colaboradores}

R. G. Oliveira contribuiu na formulação e desenho do ensaio, redação do trabalho, organização editorial e revisão crítica do conteúdo. A. G. S. Gadelha contribuiu substancialmente na redação do trabalho e revisão crítica. A. P. Cunha contribuiu substancialmente na redação do trabalho e tabulação e análise de dados. C. G. Carpio, R. B. Oliveira e R. M. Corrêa contribuíram substancialmente na redação do trabalho. Todos os autores aprovaram a versão final do artigo para publicação.

\section{Informações adicionais}

ORCID: Roberta Gondim de Oliveira (0000-00018408-6427); Ana Giselle dos Santos Gadelha (00000001-7767-4642); Ana Paula da Cunha (00000002-1400-1472); Christiane Goulart Carpio (0000-0002-7710-3791); Rachel Barros de Oliveira (0000-0002-4293-1853); Roseane Maria Corrêa (0000-0001-8542-1143).

\section{Referências}

1. World Health Organization. Statement on the second meeting of the International Health Regulations. Emergency Committee regarding the outbreak of novel coronavirus (2019-nCoV). https://www.who.int/newsroom/detail/30-01-2020-statement-on-thesecond-meeting-of-the-international-healthregulations-(2005)-emergency-committeeregarding-the-outbreak-of-novel-coronavi rus-(2019-ncov) (acessado em 07/Mai/2020).

2. Castro LR, Nogueira CO. Quem deve se preocupar? Zika como uma epidemia de mosquitos e mulheres (e algumas reflexões sobre o COVID-19). http://somatosphere.net/2020/ zika-epidemic-mosquitos-women.html/ (acessado em 06/Mai/2020).

3. Satomi E, Souza PMR, Costa TB, Reingenheim C, Werebe E, Troster EJ, et al. Alocação justa de recursos de saúde escassos diante da pandemia de COVID-19: considerações éticas. Einstein (São Paulo) 2020; 18:eAE5775.

4. Mulinari F. Ética e justiça social em tempos de pandemia. https://hcommons.org/deposits/ objects/hc:29826/datastreams/CONTENT/ content (acessado em 29/Mai/2020).

5. Kretzer L, Berbigier E, Lisboa R, Grumann AC, Andrade J. Recomendações da AMIB (Associação de Medicina Intensiva Brasileira), ABRAMEDE (Associação Brasileira de Medicina de Emergência, SBGG (Sociedade Brasileira de Geriatria e Gerontologia) e ANCP (Academia Nacional de Cuidados Paliativos) de alocação de recursos em esgotamento durante a pandemia por COVID-19. https:// sbgg.org.br/recomendacoes-da-amib-asso ciacao-de-medicina-intensiva-brasileira-abra mede-associacao-brasileira-de-medicinade-emergencia-sbgg-sociedade-brasileira-degeriatria-e-gerontologia-e-ancp-academia/ (acessado em 29/Mai/2020). 
6. Nascimento A. O genocídio do negro brasileiro: processo de um racismo mascarado. Rio de Janeiro: Editora Paz e Terra; 1978.

7. Guimarães ASA. Democracia racial: o ideal, o pacto e o mito. http://www.anpocs.com/index. $\mathrm{php} /$ encontros/papers/25-encontro-anualda-anpocs/st-4/st20-3/4678-aguimaraes-de mocracia/file (acessado em 02/Mai/2020).

8. Munanga K. Uma abordagem conceitual das noções de raça, racismo, identidade e etnia. In: Brandão AAP, organizador. Programa de educação sobre o negro na sociedade brasileira. Niterói: EdUFF; 2000. p. 15-34.

9. Munanga K. Discutindo a mestiçagem no Brasil: identidade nacional versus identidade negra. 5a Ed. Belo Horizonte: Autêntica; 2019.

10. Mbembe A. Necropolítica. São Paulo: N-1; 2018.

11. Mbembe A. Crítica da razão negra. São Paulo: $\mathrm{N}-1 ; 2018$.

12. Maldonado-Torres N. Analítica da colonialidade e da decolonialidade: algumas dimensões básicas. In: Bernandino-Costa J, MaldonadoTorres N, Grosfoguel R, organizadores. Decolonialidade e pensamento diaspórico. Belo Horizonte: Autêntica; 2018. p. 27-53.

13. Mignolo W. La colonialidad: la cara oculta de la modernidad. In: Mignolo W, organizador. Desobediencia epistêmica: retorica de la modernidade, lógica de la colonialidad y gramática de la descolonialidad. Buenos Aires: Ediciones del Signo; 2010. p. 39-49.

14. Oliveira RG. Práticas de saúde em contextos de vulnerabilização e negligência de doenças, sujeitos e territórios: potencialidades e contradições na atenção à saúde de pessoas em situação de rua. Saúde Soc 2018; 27:37-50.

15. Quijano A. Colonialidade do poder e classificação social. In: Santos BS, Meneses MP, organizadores. Epistemologias do Sul. São Paulo: Cortez; 2010. p. 84-130.

16. Maldonado-Torres N. Sobre la colonialidad del ser: contribuciones al desarrollo de un concepto. In: Castro-Gómez S, Grosfoguel R, organizadores. El giro decolonial. Reflexiones para una diversidad epistémica más allá del capitalismo global. Bogotá: Instituto Pensar, Pontificia Universidad Javeriana/Instituto de Estudios Sociales Contemporáneos, Universidad Central/Siglo del Hombre Editores; 2007. p. 127-67.

17. Kilomba G. Memórias da plantação. Rio de Janeiro: Cobogó; 2019.

18. Almeida S. Racismo estrutural. São Paulo: Pólen; 2019.

19. Bauman Z. Vidas desperdiçadas. Rio de Janeiro: Zahar; 2005.

20. Chalhoub S. Cidade febril: cortiços e epidemias na Corte Imperial. São Paulo: Companhia das Letras; 1996.

21. Hasenbalg C. Discriminação e desigualdades raciais no Brasil. 2a Ed. Rio de Janeiro: Editora UFMG; 2005.

22. Farmer P. Infection and inequalities - the modern plagues. Berkeley: University of California Press; 1999.
23. Wallerstein I. Análisis de sistemas-mundo. Una introducción. Ciudad de México: Siglo Veintiuno Editores; 2005.

24. Oliveira RG. Sentidos das doenças negligenciadas na agenda da Saúde Global: o lugar de populações e territórios. Ciênc Saúde Colet 2018; 23:2291-2302.

25. Programa das Nações Unidas para o Desenvolvimento. PNUD apresenta Relatório de Desenvolvimento Humano 2019 com dados de 189 países. https://www.br.undp.org/content/ brazil/pt/home/presscenter/articles/2019/ pnud-apresenta-relatorio-de-desenvolvimen to-humano-2019-com-dado.html (acessado em 29/Abr/2020).

26. Instituto Brasileiro de Geografia e Estatística. Desigualdades sociais por cor ou raça no Brasil. https://biblioteca.ibge.gov.br/visualizacao/ livros/liv101681_informativo.pdf (acessado em 04/Mai/2020).

27. Brasil. Decreto no 10.329. Altera o Decreto no 10.282 , de 20 de março de 2020, que regulamenta a Lei no 13.979, de 6 de fevereiro de 2020, para definir os serviços públicos e as atividades essenciais. Diário Oficial da União 2020; 29 abr.

28. Nitahara A. Negros são maioria entre desocupados e trabalhadores informais no país. Agência Brasil 2019; 13 nov. https://agenciabrasil. ebc.com.br/economia/noticia/2019-11/ne gros-sao-maioria-entre-desocupados-e-traba lhadores-informais-no-pais (acessado em 03/ Mai/2020).

29. Lima YO, Costa DM, Souza JM. Impacto COVID-19. https://impactocovid.com.br/ (acessado em 03/Mai/2020).

30. Conselho Federal de Enfermagem. Brasil tem 30 mortes na enfermagem por Covid-19 e $4 \mathrm{mil}$ profissionais afastados. http://www.cofen.gov. br/brasil-tem-30-mortes-na-enfermagempor-covid-19-e-4-mil-profissionais-afasta dos_79198.html (acessado em 03/Mai/2020).

31. Conselho Federal de Enfermagem. Gabinete de crise monitora impacto da pandemia de Covid-19. http://www.cofen.gov.br/gabine te-de-crise-monitora-impacto-da-pandemiade-covid-19_79453.html (acessado em 03/ Mai/2020).

32. Fundação Oswaldo Cruz, Conselho Federal de Enfermagem. Perfil da enfermagem no Brasil. http://www.cofen.gov.br/perfilenfermagem/ index.html (acessado em 03/Mai/2020).

33. Conselho Federal de Enfermagem. Vitória do Cofen garante proteção a profissionais em grupos de risco. http://www.cofen.gov. $\mathrm{br} /$ vitoria-do-cofen-garante-protecao-a-pro fissionais-em-grupos-de-risco_79503.html (acessado em 05/Mai/2020).

34. Croda JHR, Garcia LP. Resposta imediata da vigilância em saúde à epidemia da COVID-19. Epidemiol Serv Saúde 2020; 29:e2020002.

35. Ministério da Saúde. Portaria MS/GM no 188 , de 3 de fevereiro de 2020. Declara Emergência em Saúde Pública de Importância Nacional (ESPIN) em decorrência da Infecção Humana pelo novo Coronavírus (2019-nCoV). Diário Oficial da União 2020; 4 fev. 
36. Ministério da Saúde. Painel COVID-19. https://covid.saude.gov.br/ (acessado em 31/ Mai/2020).

37. Rede Nossa São Paulo. Mapa da desigualdade 2017. https://www.nossasaopaulo.org.br/por tal/arquivos/mapa-da-desigualdade-2017.pdf (acessado em 31/Mai/2020).

38. Rede Nossa São Paulo. Mapa da desigualdade 2016. https://www.nossasaopaulo.org.br/ar qs/mapa-da-desigualdade-completo-2016.pdf (acessado em 31/Mai/2020).

39. Secretaria Municipal de Saúde de São Paulo. COVID-19 relatório situacional, 2020; 29 mai. https://www.prefeitura.sp.gov.br/cidade/ secretarias/upload/saude/COVID19_Relato rio_SItuacional_SMS_20200529.pdf (acessado em 31/Mai/2020).

40. Rede Nossa São Paulo. A desigualdade na distribuição das UTIs em São Paulo. 2020. https:// www.nossasaopaulo.org.br/2020/04/08/a-de sigualdade-na-distribuicao-das-utis-em-sao paulo/ (acessado em 03/Mai/2020).

41. Prefeitura Municipal de Fortaleza. Informe semanal Covid-19 - 22a Semana Epidemiológica, 2020. https://coronavirus.fortaleza. ce.gov.br/pdfs/informe-semanal-covid-19-se22a-2020-sms-fortaleza.pdf (acessado em 31/ Mai/2020).

42. Ministério da Saúde. Painel de leitos e insumos. https://covid-insumos.saude.gov.br/pai neis/insumos/painel_leitos.php (acessado em 03/Mai/2020).

43. Secretaria Especial de Saúde Indígena. Boletim Epidemiológico SESAI - COVID19. https:// saudeindigena.saude.gov.br/ (acessado em 31/ Mai/2020).

44. Voz das Comunidades. Painel COVID-19 nas Favelas, 2020. https://painel.vozdascomunida des.com.br/ (acessado em 31/Mai/2020).

45. Prefeitura da Cidade do Rio de Janeiro. Painel Rio COVID-19, 2020. https://experience. arcgis.com/experience/38efc69787a346959c9 31568bd9e2cc4 (acessado em 07/Mai/2020).

46. RJ: Duque de Caxias usa câmara resfriada para guardar mortos pela covid-19. UOL 2020; 24 abr. https://noticias.uol.com.br/saude/ultimas-noticias/redacao/2020/04/24/duquede-caxias-camara-frigorifica.htm?aff_source= 56d95533a8284936a374e3a6da3d7996 (acessado em 10/Mai/2020).

47. Secretaria de Estado de Saúde do Rio de Janeiro. Painel coronavírus COVID-19. http://pai nel.saude.rj.gov.br/monitoramento/covid19. html (acessado em 31/Mai/2020).

48. Costa JB, Maldonado-Torres N, Grosfoguel R, organizadores. Decolonialidade e pensamento afrodiaspórico. Belo Horizonte: Autêntica; 2018.

49. Cunha EMGP. Recorte étnico-racial: caminhos trilhados e novos desafios. In: Batista LE, Werneck J, Lopes F, organizadores. Saúde da população negra. Brasília: Associação Brasileira de Pesquisadores/as Negros/as; 2012. p. 22-33.

50. Gomes NL. O movimento negro educador. Petrópolis: Editora Vozes; 2017.
51. Ministério da Saúde. Portaria no 344, de 1o de fevereiro de 2017. Dispõe sobre o preenchimento do quesito raça/cor nos formulários dos sistemas de informação em saúde. Diário Oficial da União 2017; 2 feb.

52. Departamento de Apoio à Gestão Participativa, Secretaria de Gestão Estratégica e Participativa, Ministério da Saúde. Política Nacional da Saúde Integral da População Negra: uma política para o SUS. 2a Ed. Brasília: Ministério da Saúde; 2013.

53. Werneck J. Racismo institucional e saúde da população negra. Saúde Soc 2016; 25:535-49.

54. Milam AJ, Furr-Holden D, Edwards-Johnson J, Webb B, Patton JW, Ezekwemba NC, et al. Are clinicians contributing to excess African American COVID-19 deaths? Unbeknownst to them, they may be. Health Equity 2020; 4:13941.

55. Daniels RJ, Morial MH. The covid-19 racial disparities could be even worse than we think. The Washington Post 2020; 23 abr. https://www.washingtonpost.com/opin ions/2020/04/23/covid-19-racial-dispari ties-could-be-even-worse-than-we-think/ (acessado em 02/Mai/2020).

56. Dorn A, Cooney RE, Sabin ML. COVID-19 exacerbating inequalities in the US. Lancet 2020; 395:1243-4.

57. Bailey ZD, Krieger N, Agénor M, Graves J, Linos N, Bassett MT. Structural racism and health inequities in the USA: evidence and interventions. Lancet 2017; 389:1453-63.

58. United States Census. Quick facts. https:// www.census.gov/quickfacts/fact/table/US/ PST045219 (acessado em 16/Mai/2020).

59. Odeveza J. Justiça determina registro obrigatório de raça em casos da Covid-19. JusDh 2020; 6 may. http://www.jusdh.org.br/2020/05/06/ justica-determina-registro-obrigatorio-de-ra ca-em-casos-da-covid-19/ (acessado em 16/ $\mathrm{Mai} / 2020)$.

60. Ministério da Saúde. Boletim Epidemiológico 09. Situação epidemiológica da Covid-19 2020. https://portalarquivos.saude.gov.br/images/ pdf/2020/April/12/2020-04-11-BE9-Boletimdo-COE.pdf (acessado em 14/Mai/2020).

61. Petruccelli JL, Saboia AL, organizdores. Características étnico-raciais da população: classificações e identidades. Rio de Janeiro: Instituto Brasileiro de Geografia e Estatística; 2013.

62. Osorio RG. O sistema classificatório de "cor ou raça” do IBGE. Brasília: Instituto de Pesquisa Econômica Aplicada; 2003. (Texto para Discussão, 996).

63. Batista A, Antunes B, Faveret G, Peres I, Marchesi J, Cunha JP, et al. Análise socioeconômica da taxa de letalidade da COVID-19 no Brasil - Nota Técnica 11. Núcleo de Operações e Inteligência em Saúde 2020; 25 mai. https:// drive.google.com/file/d/1tSU7mV4OPnLRFMMY47JIXZgzkklvkydO/view (acessado em 06/Jul/2020).

64. Schucman LV. Entre o encardido, o branco e o branquíssimo: branquitude, hierarquia e poder na cidade de São Paulo. São Paulo: Annablume; 2014. 


\section{Abstract}

COVID-19 incidence and mortality in countries with heavy social inequalities differ in population terms. In countries like Brazil with colonial histories and traditions, the social markers of differences are heavily anchored in social and racial demarcation, and the political and social dynamics and processes based on structural racism act on this demarcation. The pandemic's actual profile in Brazil clashes with narratives according to which COVID-19 is a democratic pandemic, an argument aligned with the rhetoric of racial democracy that represents a powerful strategy aimed at maintaining the subaltern place of racialized populations such as indigenous peoples and blacks, as a product of modern coloniality. This essay focuses on the pandemic's profile in the Brazilian black population, in dialogue with decolonial contributions and critical readings of racism. The authors discuss government responses and COVID-19 indicators according to race/color, demonstrating the maintenance of historical storylines that continue to threaten black lives. The article also discusses the importance of local resistance movements, organized in the favelas, precarious urban spaces underserved by the State and occupied by black Brazilians.

COVID-19; Racism; Social Vulnerability

\section{Resumen}

La incidencia y mortalidad por COVID-19 en países con fuertes desigualdades sociales se diferencian en términos poblacional. En países con historial y tradición colonial, como Brasil, los marcadores sociales de las diferencias están profundamente anclados en la demarcación sociorracial, sobre la que actúan las dinámicas y los procesos políticosociales fundamentados en el racismo estructural. Se contraponen las narraciones que proponen una lectura sobre esta pandemia democrática, cuyo argumento se alinea con la retórica de la democracia racial, que corresponde a una potente estrategia de mantenimiento del lugar de poblaciones racializadas, como indígenas y negros, producto del colonialismo moderno. Este ensayo se centra sobre el comportamiento de la pandemia respecto a la población negra en Brasil, en diálogo con aportes decoloniales y lecturas críticas sobre el racismo. Se discuten respuestas gubernamentales e indicadores de la enfermedad, según la categoría raza/color demostrando el mantenimiento de entramados y enredos históricos que siguen vulnerabilizando e inviabilizando vidas negras. Se apunta también la importancia de movimientos de resistencia locales, operados a partir del lugar que estos individuos ocupan, espacios urbanos precarizados por acción/ omisión del Estado: las favelas.

COVID-19; Racismo; Vulnerabilidad Social
Recebido em 03/Jun/2020

Versão final reapresentada em 08/Jul/2020 Aprovado em 17/Jul/2020 